\title{
PRESÈNCIA I CARACTERÍSTIQUES DELS ELEMENTS MÈDICS EN LES MIL I UNA NITS
}

\author{
Emili BALAGUER PERIGÜEL \\ Rosa BALLESTER AÑóN \\ Universitat d'Alacant
}

Les mil $i$ una nits és un dels grans monuments de la narrativa àrab. La seua procedència diversa $i$ la gran varietat del contingut fan d'aquesta obra literària impressionant un model ideal d'aquella cultura'. L'objectiu del nostre article és un estudi de la presència de la medicina en les seues histories i els seus contes tenint en compte la importància que el saber mèdic va tenir en el món de l'Islam. Amb la nostra aportaci 6 ens volem unir a tots els qui en aquest volum reten homenatge de gratitud a la professora Maria Jesús Rubiera Mata per la seua dedicació generosa al servei de la nostra Universitat i del seu desenvolupament científic.

\section{La trobada necessària amb el saber antic}

La trobada de l'Islam amb el vell saber hel-lènic era inevitable. Assentats sobre el marc historico-geogràfic del món hel-lenitzat i en contacte amb el neoplatonisme cristia oriental, semblants problemes religiosos i polítics, la vida espiritual naixent i l'inici dels problemes

${ }^{1}$ Hem usat la traducció de les Mil y una noches al castellà de Juan Vernet, Barcelona, Planeta, 1990, 2 vols. La traducció al català és nostra. Per a citar el text amb la finalitat d'una precisió major farem referència al número de nit, el volum i la pàgina. 
teologics necessitaven un marc adequat de formes i mètodes que els estructuraren.

El pensament teologic, filosòfic i científic de l'Islam - ja que en l'escolàstica àrab com en la cristiana, no hem de parlar de filosofia estricta- s'ordena i s'estructura en rebre les formes i els mètodes de la filosofia grega. El primer Kaläm es limita a acumular la casuística i a interpretar literalment la llei. Quan l'heurística literalista va ser insuficient, la interpretació va recórrer a les fórmules populars del neoplatonisme ja prèviament cristianitzat.

De la síntesi neoplatònica musulmana parteix també l'esforç científic dels grans pensadors escolàstics àrabs. Però, impressionats per la força del corpus aristotelicum - que els àrabs van conéixer íntegrament, tret de la Poltica-, van iniciar una tasca critica important que va originar una depuració progressiva en la recerca d'un saber cientific cada vegada més estricte, és a dir, cada vegada més aristotèlic. Ara bé, les exigències de la teología de la creació, comuna a l'escolàstica jueva, cristiana i musulmana, no van permetre una filosofia estricta a la manera grega, sinó que van forçar un compromís entre l'aristotelisme pur i el neoplatonisme ${ }^{2}$. La medicina va obtenir aviat el seu lloc dins de la classificació total de les ciències a mesura que avançava la recepcio d'Aristotil. Com a part de la gran natura, l'home es declara objecte de la flsica; a la medicina se li dóna, com a disciplina científica, un lloc sistemàtic, i al metge una terminologia obligatoria. Com a fisica apareix també la medicina en el clàssic Cataleg de les ciències d'alFārābī (870-950), considerat un dels millors coneixedors d'Aristotil en la seua època $\mathrm{i}$ amb coneixements extraordinaris de medicina ${ }^{3}$.

La posició d'un mestre de medicina no pot ser considerada en la seua dimensió autentica si no es pren com a base la idea original de hakim. Al-hakim, seria doncs el savi, el mestre per excel-lència i també el filosof. Va ser un gran honor científic per al metge àrab el fet que

${ }^{2}$ Cruz Hernández, Miguel, "Visión sinóptica de la cultura islámica", dins P. Laín Entralgo, Historia universal de la medicina, Barcelona, Salvat, 1981, vol. III, pàgs. 41-56.

${ }^{3}$ Schipperges, Heinrich, "La medicina en el medievo árabe", dins P. Laín Entralgo, Historia universal de la medicina, Barcelona, Salvat, 1981, vol. III, pàg. 66. 
aquest títol general de la cultura àrab s'encunyara totalment en el metge. Alhora que com a ciencia de la natura, com a fisica, la medicina va poder esdevenir, en l'obra d'Avicenna (980-1307), el fonament de la ciència total $\mathrm{i}$, juntament amb l'astronomia, la geometria i la música, fonament de la bona educació, segons el savi universal de Bàssora Abū 'Uțmān 'Amr ibn al-Kimānī al-Fugaymī al-Bașrī (777-869).

El caràcter cosmopolita i la tolerància intel lectual es troben també en el primer gran filosof de la medicina àrab, al-Kindī (mort després del 810), quan diu: "No ens hauríem d'avergonyir de reconéixer la veritat i acceptar-la vinga de la font que vinga, fins i tot encara que ens haja estat proporcionada per generacions antigues i pobles estranys. Jo em base en les citacions completes del que els antics van escriure sobre el tema i, a més, considere tot allo que no van dir totalment, segons la nostra llengua àrab, els costums dels nostres dies i la nostra capacitat". De la mateixa manera destaquen sempre en aquesta posició comprensiva al-Fārābī i Averrois (1126-1198).

Però el metge àrab no es limita a l'especulació pura, sinó que intenta buscar l'equilibri entre la teoria i la pràctica. Dos exemples significatius: el d'un clínic de caràcter tan pragmàtic com Rāzì (mort el 923) i el gran teòric, ja esmentat anteriorment, al-Fārābī. En un dels aforismes més difosos de Rāzī es pot llegir: "qui no es dedica a meditar sobre els secrets de la medicina i sobre les ciencies logiques, etiques $\mathrm{i}$ matemàtiques, qui es dedica principalment als plaers mundans és sospitós, almenys en medicina. Només quan Aristòtil i Galé estan d'acord sobre una cosa, aquesta pot ser possiblement veritat; però si difereixen, trobar la veritat és més difícil per a la raó"4. Per la seua part al-Fārābì distingeix en la medicina, com en la resta de les ciències, dos camps: una ars activa i una ars speculativa. La teoria s'entén bé com a ensenyament, bé com a observacio, mentre que la praxi és el procediment manual, l'operació; ambdues parts originen la totalitat, la regla (qãnün). Acf, l'activitat manual no té la connotació de 'servil' pròpia de l'hel-lenisme, malgrat la gran influència d'Aristòtil. Però, a més, des d'un principi, s'hi inclou també la imaginació que, amb una

${ }^{4}$ Schipperges, Idem, pàg. 75. 
força creadora especial, conforma tots els camps pràctics i així és capaç d'acompanyar i tenir cura de la tasca mèdica quotidiana.

\section{Cronologia de la recepció}

A partir del segle II després de Crist es va dur a terme una gran activitat missionera vers l'orient que va partir dels centres culturals siríacs. Nisibis i Edessa van ser els centres de la civilització siŕaca on la medicina científica, juntament amb la teologia i la filologia, es va desenvolupar i es va conrear cristianament.

Els portadors d'aquest moviment cultural van ser sobretot els nestorians, i la destinació d'aquests emigrants va ser decisiva per al desenvolupament de les ciències. Expulsats de l'imperi Bizantí, es van establir primer a Síria. L'any 489 van ser expulsats de la capital, Edessa, i van trobar asil entre els sassànides, dinastia dirigent de Pèrsia. Ací van fundar, a imitació dels alexandrins, un centre d'ensenyament de medicina a l'antiga ciutat de Gondēsāpūr.

Fins a finals del segle V, Síria i Antioquia van ser, sota la influència hel-lenística, les grans mitjanceres entre la cultura grega $i$ l'oriental, i els jacobites i els nestorians es van dedicar a l'educacio professional de mestres, jutges i metges. Des de finals del segle $V$, aquest paper se centra cada vegada més a Gondēsāpūr com a centre d'ensenyament acadèmic nou. Després del tancament de l'escola d'Edessa, l'any 489, Sapor II va oferir generosament asil als emigrants savis, però poc després van arribar els de l'escola d'Atenes, tancada l'any 529. Principalment són els metges nestorians els qui busquen una integració ràpida de la medicina grega i les idees zoroàstriques de la cultura persa, com també d'elements procedents de la medicina índia.

El segle VII es va formar a Gondesāpūr un centre superior d'ensenyament que portava l'honrós nom d'Acadèmia Hipocràtica, que permet considerar-la la primera metropoli cientffica de l'Orient. No solament era un pont entre l'Hel-lade i l'Islam, sinó també un centre integrador de la cultura alexandrina $i$ de l'Orient Llunyà. Aquesta evolució segueix una direcció totalment nova $\mathrm{i}$ assoleix significació universal en caure Pèrsia sota la sobirania àrab el segle VII.

A finals del segle VIII, el centre receptor es va traslladant cada vegada més a Bagdad, que com a metròpoli dels abbàssides no solament 
és el centre d'enllaç de les vies comercials d'Àsia anterior i lloc de reunió de tradicions orientals antigues, sinó també el centre cristal litzador de les noves ciències. Certament, l'escola de Gondēsāpūr va ser el punt de partida decisiu d'aquest desenvolupament. Els historiadors àrabs solen contar una anècdota que, fins i tot, pot ser certa històricament. L'any 765, al-Manșūr, segon califa de la dinastia abbàssida, va emmalaltir en la nova ciutat imperial, Bagdad; cap dels metges musulmans va aconseguir remeiar la malaltia. Aleshores, advertit per la fama que tenia, va cridar un metge cristià nestorià anomenat Girgīs ibn Gibril, director de l'hospital de Gundēsāpūr. Girgīs va aconseguir que el califa sanara, i el monarca, agraït, a més de premiar-lo i nomenar-lo metge de cambra, es va interessar per les fonts del seu saber científic. Com que el metge li va parlar d'Hipòcrates, Dioscòrides, Aristòtil i Galé, el califa va ordenar la traducció de les seues obres $^{5}$. Amb aixo es van fer els primers contactes que formarien a Bagdad un centre nou, mantingut sobretot per la dinastia dels metges Buhtīsū. En aquesta època, Bagdad és l'elegant metròpoli dels abbàssides i, a més, el centre de les vies comercials asiàtiques, la faula de les Mil $i$ una nits i no precisament en l'últim lloc, el centre científic nou de l'Imperi, sobretot després que el califa al-Ma'mün (813-833) fundara ací la seua biblioteca reial, el centre director indiscutible de tot el món culte, el Bayt al-Hikma (Casa de la Saviesa). En aquesta institució és on el siríac Hunayn ibn Ishãq desenvolupa la seua important activitat $i$ organitza una escola de traductors.

Abū Zayd Hụnayn ibn Ishạā al-Ibādī va nàixer l'any 809 a Hīra fill d'un apotecari cristià. Va estudiar a Bassora i després a Bagdad. Va viatjar a l'Àsia Menor, on va adquirir excel·lents coneixements de la llengua grega. Després del seu retorn, es va establir a Bagdad com a mestre de medicina i alhora va ser metge de cambra del califa alMutawakkil, que va donar un suport generós als seus projectes. Acr va començar les seues traduccions del grec, tan decisives per al progrés islàmic i occidental. A Hunayn se li pot atribuir l'honor d'haver traduït l'obra completa de Galé. D'aquesta manera es van transmetre les obres del gran metge grec, perdudes per a la tradició hel-lenística.

\footnotetext{
${ }^{5}$ Cruz Hernảndez, ob. cit., pàg. 53.
} 
L'activitat i l'erudició desenvolupades a la Casa de la Saviesa no es poden imaginar amb exactitud. Hunayn ibn Isḥāq estava en realitat al front d'un centre complet de traductors que treballava amb criteris filologics moderns. Hunayn investigava sistemàticament els manuscrits grecs, els acarava per a obtenir un text correcte, que després comparava amb la traducció siríaca i dictava les correccions als seus ajudants; només aleshores començava la traducció a l'àrab.

No és arriscat afirmar que l'amplitud de la medicina grega solament la podem conéixer a través de les traduccions àrabs. Al llarg del 800 , amb els abbàssides, s'ha completat quasi la recepció de Grècia, Iran i Índia. Amb els búyides (932-1055) podem considerar que la recepció ha acabat. Comença un fase d'assimilació profunda, en la qual domina com a figura fonamental Aristòtil i on l'expressió més representativa és la sistemàtica de les ciències d'Avicenna. D'altra banda, el filosof alGazzālī (mort el 1111), va intentar una síntesi de fe i de ciència. En definitiva, a mitjans del segle IX els àrabs ja coneixen les ciències naturals de l'antiguitat. Lligen íntegrament Aristotil, Galé i el Corpus Hippocraticum. Aquestes autoritats creen el nou tipus de savi secular, el hakim, filossof mèdic, portador representatiu de la cultura àrab de salvació.

\section{La presència de la medicina en les Mil $i$ una nits}

Els inicis de la medicina àrab són purament empírics i pragmàtics, i no disposem de fonts sobre l'època pre-islàmica. No hem de suposar una medicina beduïna independent que sobrepassa la medicina popular usual i alguns elements d'aquesta, pocs, apareixen en les Mil $i$ una nits. L'Alcorà està ple, pel contrari, de regles de vida higiènica i d'indicacions dietètiques que posteriorment es van reunir com Tibb al-Nabi (medicina del Profeta) i alguna d'aquestes es reflecteixen en la vida quotidiana dels personatges, mentre altres són habitualment incomplides. No obstant aixd, no hem de fer afirmacions precipitades. Mahoma sembla haver adoptat davant la medicina una postura oberta i tolerant, segons afirma la tradició tardana. Una frase del Profeta diu: "Si un malalt demana alguna cosa, cal donar-li-la". També és clara la 
formulació: "Només hi ha dues ciències, la teologia (salvació de l'ànima) i la medicina (salvació dels cos)" .

Centrarem el nostre estudi en la manera en que apareixen i s'integren en la narrativa elements procedents de la medicina grega i hel-lenística. No solament perquè quantitativament són més importants que els perses o els indis, sinó perquè el seu paper en la cultura àrab també va ser més decisiu.

\subsection{La medicina, part de la cultura}

Ja hem assenyalat anteriorment la importància social de la medicina en la bona educació, fet que es reflecteix en nombrosos episodis pero de manera molt especial en la Història del rei Umar al-Numán i dels seus dos fills, Sarkan i Daw Al-Makán, posteriorment al segle XIII pels personatges que esmenta. La princesa Nuzhat al-Zaman, que diu que s'ha educat amb la filla del rei Umar, senyor de Bagdad, quan descriu els seus coneixements diu que, a més d'aprendre l'Alcorà de memoria, "[...] conec la filosofia, la medicina, la logica, el comentari dels capítols d'Hipòcrates escrit per Galé, el filósof, [...] he estudiat el Mufradat d'Ibn al-Bayțār ${ }^{7} \mathrm{i}$ he parlat sobre el Canon d'Avicenna; [...] he explicat geometria i sé a la perfecció la ciencia dels cossos; he llegit els llibres dels safiies, he estudiat la tradició i la gramàtica $[\ldots] \mathrm{He}$ estudiat totes les ciències"8.

Fins i tot, quan es fa referencia a la medicina com a activitat professional, es distingeix entre la condició del metge pràctic, com el jueu del conte El geperut, el jueu, el superintendent $i$ el cristia, amb una actitud pragmàtica ${ }^{9} \mathrm{i}$ el veritable haktm, el savi que apareix més freqüentment. Exemple paradigmàtic és el metge Rayán de qui es diu que "coneixia perfectament els llibres grecs, perses, romans, àrabs i

${ }^{6}$ Schipperges, ob. cit., pàg. 65.

${ }^{7}$ Farmacòleg hispano-musulmà del segle XIII, autor entre altres escrits, d'un tractat que estudiava per ordre alfabètic més de mil quatre-cents medicaments, dels quals tres-cents són nous.

${ }^{8}$ Nit 58, vol. 1, pàgs. 379-380.

${ }^{9}$ Nit 25, vol. 1, pàgs. 172-184. 
siríacs; dominava la medicina i l'astrologia, de les quals coneixia les causes, la manera en què aquestes obraven i les coses que eren perjudicials o favorables; sabia les propietats de les plantes de les drogues $\mathrm{i}$ de les herbes, foren nocives o útils. Bon filosof, coneixia totes les ciències de la medicina i encara més" ${ }^{10}$.

En un altre episodi, el metge persa es descriu a si mateix com a "savi" quan s'adreça al rei i afirma: "En persa em dic Harcha [...] sóc savi i la meua especialitat és la medicina. Sane les malalties i els bojos. Recorrec els països i les ciutats amb la finalitat d'augmentar els meus coneixements. Quan trobe un malalt el guaresc"11. Una actitud típica del metge savi i que es reflecteix clarament en les paraules de Harcha és el seu caràcter viatger. La primera tasca del metge culte no és de cap manera l'operatio, sinó una peregrinatio conreadora i directora. Els joves savis buscaven en viatges d'estudis aventurers la seua gran vivència cientifica que sabien trobar generalment en la tradició hel-lenística. Viatjaven fins a Bukhara i Samarcanda per a escoltar un mestre famós, fins i tot a l'Índia i a la Xina. Sempre els acompanyava una altra frase del profeta: "Qui deixa sa casa per a dedicar-se a la ciència, segueix els camins d'Alà fins al dia del seu retorn"12.

\subsection{El concepte de natura}

Un dels problemes filosòfics de la cultura islàmica, com també de la teologia cristiana, va ser fer compatible el principi de physis de la ciència grega amb la seua concepció del món. Per a un científic grec, la physis és el principi del moviment i del repós, "la causa de l'ordre total", va escriure Aristotil ${ }^{13}$.

L'àrab pre-islàmic (i també en l'Islam), manté la concepció de la diferència ontològica entre el Creador i l'ésser creat; però a l'hora de caracteritzar l'home com a ser entre Creador i creat, minimitza el

${ }^{10}$ El ministre del rei Yuman i el savi Ruyan, nit 4, vol. I, pàgs. 32-33.

${ }^{11}$ Història del cavall d'eben, nit 369, vol. I, pàg. 1207.

${ }^{12}$ Schipperges, ob. cit., pàg. 71.

${ }^{13}$ Laín Entralgo, P.-López Piñero, J.M., Panorama histórico de la ciencia moderna, Madrid, Ed. Guadarrama, 1962, pàgs. 22-23. 
primer constitutiu. L'home no és la culminació de la physis, a la manera grega. El fet fonamental de l'home és ser també un ésser creat més, tan fugisser com les coses i tan subjecte a l'atzar-destí com aquestes. La inserció de la cultura àrab, a partir de Mahoma, en el món de la profecia, va accentuar més aquestes diferències. La veritat per al Profeta és la paraula de Déu, que es manifesta a través dels profetes i en el temps. La veritat no és un fet natural, no està en la physis, sinó que és quelcom que depén del temps que ha de venir ${ }^{14}$.

Si considerem el contingut del Hadit (la medicina del Profeta), es veu també que la seua posició dins la societat àrab hi portava sempre quelcom d'ambivalent als ulls de la tradició ortodoxa. De l'Alcorà es poden extraure -segons Schipperges- testimonis suficients que documenten la postura contradictoria del mateix Profeta. Pero la doctrina islàmica de la predestinació no va rebutjar mai la intervenció mèdica. El mateix Profeta, segons la tradició pietosa, sembla haver donat suport a aquesta postura amb la seua actitud amb els malalts ${ }^{15}$. Això no exclou tensions constants entre la teologia $i$ la medicina. D'altra banda l'Alcord vol reglamentar amb el benestar espiritual, el corporal; mentre que metges com al-Ṭabarī o al-Ruhāwī, segueixen la tradició hel-lenística i entenen la medicina com a l'art del guariment del cos i de l'ànima.

La forma en què es va resoldre aquesta tensió és, de vegades, la utilització d'una fórmula retorica de compromís que no altera ni l'estructura conceptual de la medicina hel-lenística, ni la religiositat del haktm: "espere que Déu la sane per la meua mà"16.

Per al metge àrab usar el concepte de physis com postula la medicina grega i hel-lenística per a l'home, va plantejar pocs problemes si s'adaptava a la tradició somaticista furibunda d'aquella. Per a Galé, la physis de cadascun dels individus es manifestava en el seu temperament i les seues característiques variaven segons aquest, el sexe, l'edat, etc.

\footnotetext{
${ }^{14}$ Cruz Hernández, ob. cit., pàgs. 43-44.

15 Schipperges, ob, cit., pàgs. 65-66.

${ }^{16}$ Història del cavall d'eben, nit 369, vol. I, pàg. 1207.
} 
Fins i tot les propietats de l'anima estaven determinades per la constitució somàtica o corporal, subjecte únic de la malaltia ${ }^{17}$.

El jove enamorat de l'Historia d'Aziz $i$ Aziza havia de seguir unes pautes de comportament segons la seua edat i la seua preocupacio: "Tu estaves dormint, tip de menjar, fins al punt de causar repulsió a les persones $i$, per aixo, calia salar-te, perque la teua natura no es corrompa, ja que dius que estàs boig d'amor quan el son està prohibit per als amants [...] perque tot $\mathrm{i}$ ser tan jove només et preocupa menjar, beure i dormir"18.

En un altre lloc, es fa referència a les tendències homosexuals i es diu que "quan el temperament i la natura estan corruptes, no valen raons" ${ }^{19}$. El mateix concepte de natura subjau en la idea que la raça determina peculiaritats pròpies. La més difosa en els contes és que la potència sexual i la virilitat dels negres és major que en els blancs i en aquests més intensa en l'adult que en el jove: "Per la virilitat dels negres -encara que la nostra virilitat fóra com la dels blancs-, jure que si tornes a arribar a aquesta hora, a partir d'avui deixaré de ser el teu amant i no col-locaré mai més el meu cos damunt del teu! [...]"20. L'edat és un altre dels factors que influeix en les característiques del temperament $i$ en la forma que determina el comportament sexual de l'home i de la dona. En la història Les dues dones $i$ els seus amants, quan l'amant del jove retrau a la seua companya que suporte les molèsties del seu home adult i barbut, aquesta li contesta: "Com podria posar-me davall d'un adolescent que va més ràpid que jo $i$ que conclou abans que jo comence i abandonar un home que quan ol, abraça, entra

${ }^{17}$ García Ballester, L., Alma y enfermedad en la obra de Galeno, València, Cuadernos Valencianos de Historia de la Medicina, 1968. Del mateix autor: "La psyché en el somaticismo médico de la Antigüedad. La actitud de Galeno", Episteme, 3, 195-209 (1969).

${ }^{18}$ Nit 116, vol. 1, pàg. 532.

19 Nit 216, vol. I, pàg. 846.

${ }^{20}$ Història del jove de pedra, nit 8, vol. I, pàg. 54. En un altre lloc, nit 38, vol. I, pàg. 287; un negre de dotze anys conta: "ella es va posar a jugar amb mi; el meu membre es va trempar, fins a tenir la grandària d'una clau gran". 
lentament $\mathrm{i}$ quan acaba torna a la càrrega; que es mou estupendament i quan conclou comença de nou?"21.

El concepte de natura, en el sentit pur de la medicina clàssica grega, adquireix una rellevància singular en el cas de la importància dels sexes i segueix el principi alcoranic de la superioritat de l'home sobre la dona. Juntament amb els arguments de tipus religiós tradicio$\mathrm{nal}^{22}$, s'intenta argumentar amb proves que "subministren l'enteniment". Les raons són de la més pura tradició aristotelica: "Els arguments racionals mostren que el mascle és actiu i la dona passiva i l'element agent té més valor que el pacient" ${ }^{23}$. La superioritat de l'home ve donada "tenint en compte la virilitat" i encara que l'edat matise aquest fet ja que "des d'aquest aspecte, el nen, el xic, el jove, l'home madur i el vell són iguals [...] Si la superioritat derivara (solament) de la seua virilitat, la teua naturalesa et faria sentir satisfet tant amb el jove com amb el vell, perquè no hi ha diferències de sexe entre ells" ${ }^{14}$. A aquest argument esgrimit per un alfaquí, se li replica amb contundència: "La més petita de les seues virtuts és que està lliure de la menstruació i de l'embaràs" ${ }^{25}$. La dona, per la seua condició, no solament és passiva sinó també negativa:

"No et refies de les dones; no cregues en les seues promeses. Estar contenta o emprenyada depén del seu sexe ${ }^{\text {n26 }}$.

Aquest fet marca el seu paper en la societat, molt variable segons el rang, de tal manera que la virginitat abans del matrimoni és d'una

21 Nit 424, vol. I, pàg. 1341. Igualment, l'edat de la dona modifica el comportament sexual perquè varia el seu temperament. En la història d'Abu Suwayd i l'anciana bella, l'anciana recita en despertar-se: "Ah d'aquells dies en què anava amb el vestit de la meua joventut i en rebia per davant i per darrere". Idem, pàg. 1340.

22 En "Discussió sobre el mèrit dels sexes", nit 420, vol, I, 1332 se cita repetidament l'Alcorà $(4,38 ; 2,282 ; 4 ; 175)$.

${ }^{23}$ Ibidem.

${ }^{24}$ Ibidem.

25 Ibidem, pàg. 1333.

${ }^{26}$ El rei Sahriyar i el seu germà Sahzaman, vol. I, pàg. 10. 
importància extraordinària ${ }^{27}$. La submissió al mascle, en moltes històries és absoluta: "Les delícies es troben en tres coses: menjar carn, cavalcar carn i ficar la carn dins la carn" ${ }^{28}$. Aquesta inferioritat intel-lectual i moral de les dones explicaria també que els únics actes de zoofflia en l'obra, siguen protagonitzats per dones ${ }^{29}$.

\subsection{Presència i característiques dels elements mèdics en les Mil $i$ una nits}

No hem d'esperar, en aquest tipus de gènere literari, una presència sistemàtica de conceptes biologics o elements medics ${ }^{30}$. No obstant aixo, si és possible rastrejar les idees mediques i biologiques que hi ha darrere d'algunes actituds i d'alguns comportaments. Pel que fa a la terminologia anatòmica, està més en funció de la força narrativa que de la precisió tècnica. En ocasions s'esmenten els "dits del cor i índex" els "pits com llunes", les "cuixes d'ivori" etc. En unes altres, la descripció anatòmica està al servei exclusiu de l'argument, com en el cas de la historia El pescador i el geni, quan descriu l'efrit: "El seu cap

${ }^{27}$ Són nombroses les al·lusions a la importància de la virginitat: "em vaig casar amb ella quan era verge, i Déu em va concedir tres fills mascles", nit 18, vol. I, pàg. 126. En aquest context, la presència dels fills mascles són un do, si considerem la importància social del mascle, "ja que saps que el mascle val més que la femella; el meu fill és mascle i nosaltres serem recordats gràcies a ell, no a la teua filla"; nit 19, vol. I, pàg. 131 .

${ }^{28}$ Història de les esclaves dels diferents colors $i$ de la discussió que va haver entre elles, nit 336, vol. I, pàg. 1135. En la història en què Dalila l'Astuta ofereix en matrimoni un jove mercader a l'esposa de l'emir Hassan Sarr al-Tariq, el jove afirma: "Li he demanat a Déu una esposa, i ell me n'ha concedit tres: una bossa, un úter i un vestit", nit 700, vol. II, pàg. 611 .

29 Història de Wardan el carnisser, la protagonista de la història manté relacions sexuals amb un ós. Nits 354-355, vol. I, pàgs. 1186-1187; i en la História que tracta del guarimen de la concupiscència excessiva de les dones, amb un mico, nit 356, vol. I, pàgs. 1186-1187.

30 Això mateix vam poder verificar en el Tirant lo Blanc: Balaguer, E. "Les idees mèdiques en el Tirant", dins Jornades commemoratives del cinc-cents aniversari, Alacant-La Nucia, Departament de Filologia Catalana, 1990.

${ }^{31}$ Nit 113, vol. 1, pàg. 520. 
es perdia entre els núvols, els seus peus s'afermaven en la pols del terra; aquell semblava la cúpula; les seues mans, reixes; els seus peus, arbres de vaixell; la seua boca una cova, les seues dents, pedres; el seu nas un porró; els seus ulls dues torxes; els seus cabells cendrosos estaven en el desordre més complet ${ }^{\prime \prime}$.

Sens dubte, els organs esmentats amb més varietat de termes, tant cientifics com simbolics i al·legorics són els sexuals. Com a exemple paradigmàtic esmentarem el quadre obscé de la Historia del faqui amb les joves que, segons Vernet, no sembla haver format part originariament d'aquest conte ${ }^{33}$.

${ }^{32}$ Nit 3, vol. I, pàg. 29.

${ }^{33}$ Nit 9 i 10, vol. 1, pàgs. 67-68: "després, en eixir de l'aigua, es va llançar als braços del jove i li va dir: "Amat meu! Com es diu açò?" I va assenyalar les seues parts. "La teua misericòrdia". "Uf! Uf! No t'avergonyeixes?" El va agafar pel coll i va començar a bufetejar-lo. Va exclamar el faquí: "És la teua vulva!" "Ca! Digues un altre nom!". "E1 teu kiss". "Ca! Digues-ne un altre". "El teu zumbur". Però ella no deixava de colpejar-lo i al final, el seu coll i el seu clatell van ser incapaços de suportar més pinyes. Li va preguntar: "Com, doncs, es diu?" "L'alfâbega dels ponts". "Lloat siga Déu per haver-me salvat, oh alfâbega dels ponts!".

De nou va tornar a circular el tinell i la copa. Llavors es va alçar la segona, es va llançar a l'estanc i va fer exactament igual que la primera. En eixir es va llançar als braços del faquí $i$, assenyalant-ne les parts va preguntar: "Llum dels meus ulls! Com es diu açò?" "La teua vulva". "No et fa vergonya dir aquestes grolleries?", i el va bufetejar de manera que tota la sala va ressonar. Va afegir "L'alfâbega dels ponts". "Ca!", li va donar colps i calbots. Va preguntar: "Com es diu?" "El sèsam escorçat".

Després, es va alçar la tercera, es va llevar la roba, es va llançar a l'estanc i va fer igual que les que l'havien precedit. En eixir, es va llançar als braços del faquí i aquest li va preguntar, fart ja de tant de colp: "Com es diu?" "La fonda Abu Mansur".

Uns moments més tard es va incorporar el faquí, es va despullar i es va clavar a l'estanc. En les aigües sobrenadava el seu membre. Es va llavar de la mateixa manera com elles ho havien fet. En eixir es va llançar damunt les seues companyes i va col-locar els braços damunt la portera i els peus sobre la compradora. Fet açò, assenyalant el seu fal-lus, va preguntar: "Senyores meues! Com es diu açò?" Tan prompte van sentir les seues paraules, les tres van trencar a riure fins que ja no podien més. Van respondre: "El teu $z i b$ ". "Que va!", i va fer un mos a cadascuna. "La teua aira". "No!"..; al final van preguntar: "Com es diu?" "El mul dels ponts que s'alimenta d'alfábega, menja el sèsam escorçat i pernocta a la fonda d'Abu Mansur". Les tres reien tan desmesuradament que es 
L'òrgan descrit amb major precisió anatòmica és l'ull, segurament per la gran tradició oftalmologica de la medicina àrab ${ }^{34}$. Com a expressió màxima del dolor es parla "d'una agulla en el llagrimall"35 i té una bellesa literària especial la descripció de l'anatomia de l'ull per a referir-se a alguns esdeveniments: l'esclava Qut al-Qulub "va dirigir l'esguard vers el carrer i va veure que gent sospitosa [...] envoltava la casa, de la mateixa manera que, en l'ull la cornia envolta la pupil $\cdot$ la" ${ }^{136}$.

Les idees sobre el significat del procés embrionari són especialment interessants. És en aquest tema on la influència d'Aristòtil es manifesta amb més claredat. En diverses ocasions es parla del cor com a seu de l'ànima irascible, o dels sentiments, en un sentit aristotèlic pur ${ }^{37}$, però és en l'embriologia on es mostra amb més evidencia el pes del filosofbiòleg grec en la medicina àrab a través de la seua doctrina ontogènica de l'epigènesi ${ }^{38}$. Els exemples són nombrosos: "Gloria a Aquell que va crear l'home d'un coàgul!", exclama el poeta quan contempla la bellesa d'Alif ${ }^{39}$. Però el text més explícit en aquest sentit es troba en la Historia del rei Umar Al-Numan i els seus dos fills Sarkan i Daw AlMakan, quan descriu el comportament del mascle que vol unir-se a una

rebolcaven per terra.

$34 \mathrm{Ja}$ al Bagdad del segle IX va destacar el gran oftalmòleg Yuhanna ibn Masāway (mort el 857), i no oblidem que la primera vegada que es porta l'òptica i l'anatomia a un sistema de referència conclòs és a Ibn al-Haytām (965-1039) de Bassora, especialment en el seu Tractat sobre la substància de l'òrgan de la visió i la manera en què s'hi desenvolupa el procés de la visió.

35 Nit 16, vol. 1, pàg. 106.

36 "Història d'Ayyub, el comerciant, del seu fill Ganim i de la seua filla Fàtima"; nit 41, vol. I, pàg. 303.

37 "Déu va omplir de terror el cor dels qui quedaven", nit 50, vol. 1, pàg. 337. I en el mateix lloc, pag. 346, el príncep Sarkan "amb el cor ple d'ira, esperonava el cavall fins a arribar al costat del franc".

38 Aristòtil, amb el seu tractat De generatione animalium, crea les bases de l'embriologia científica. Segons la doctrina de l'epigènesi, el procés ontogènic seria de configuració. Fidel al seu pensament hilemòrfic, la matèria informe seria la sang menstrual femenina i la forma o la força configuradora es trobaria en el semen masculí.

${ }^{39}$ Nit 359, vol. I, pàg. 1192. 
dona i que, després d'excitar-la amb besades i carícies "[...] l'estenc d'esquenes i, quan el semen queda empresonat en el seu receptacle, dic: Déu meu! Fes que siga fecund! Que no es perda i modela'l en una bella figura!" ${ }^{40}$ El terme modelar és definitiu en la concepció epigenètica de l'embriologia. En altres contes podem trobar implícita aquesta doctrina, així que no és arriscat afirmar el seu domini ${ }^{41}$.

Del conjunt d'elements mèdics en les Mil $i$ una nits, els més abundants són els que fan referència al coit, l'embaràs i el part. El coit ideal és quan "s'arrabassa la virginitat", com ja hem comentat. En ocasions té, fins i tot, efectes terapeutics com en la historia del rei Sulayman $^{42}$; però el més important del coit rau en el plaer de la primícia. En la història de Nur Al-Din i els seu germà Xams Al-Din es descriu el coit amb totes les connotacions indicades amb un llenguatge no mancat de poesia: "Els peus d'ella el van estrényer per la cintura. De seguida va carregar el canó, el va apuntar vers la fortalesa i el va disparar; va destruir el bastió i va veure que era una perla que no havia estat perforada, $i$ un animal de càrrega que ningú no havia muntat abans que ell; va destruir la seua virginitat i en va gaudir de la joventut. Va carregar el canó $i$ el va enfrontar amb la selva quinze vegades. En acabar Badr al-Din va col-locar la seua mà davall del cap de Sitt alHusn, i aquesta va col-locar la seua davall de la d'ell [...] i van dormir abraçats" ${ }^{43}$. Pel que fa als terminis establerts per a rebutjar una dona, una idea generalitzada i que no té cap fonament científic, potser responga més a determinants jurídics o religiosos, és la creença que aquesta pot saber immediatament després del coit si ha quedat embaras-

${ }^{40}$ Nit 62, vol. I, pàg. 389.

${ }^{41}$ Si la dona és d'origen plebeu i la deixes encinta, pot portar al món un fill indigne; "... pot passar amb ella allò que passa quan se sembra en terra salada: la llaor tan sols produeix males herbes" nit 107, vol. I, pàg. 505. En una altra història, la dona acusada d'estèril pel seu home li contesta: "Tu ets l'estèril, perquè ets un mul de nas camús: el teu esperma està diluït, no deixa encinta les dones ni proporciona fills". Nit 699, vol. I, pàg. 607.

42 Nit 109, vol. I, pàg. 511.

${ }^{43}$ Nit 21, vol. I, pàg. 147. 
sada o no: "Sarkan [...] li va arrabassar la virginitat. Ella va quedar encinta aquella mateixa nit $i$ li ho va dir"44.

El naixement és descrit en alguns contes amb un detall especial. És paradigmàtic el que narra el part de l'esposa del rei Sulaymān: "[...] havia arribat l'última nit del nové mes, els dolors del part van sorprendre la seua esposa de matinada. Va seure en la cadira de les parteres $i$ Déu li va facilitar el part i va naixer un fill mascle... Les nodrisses van agafar el nadó, van tallar el cordó umbilical i li van posar col-liri als ulls $[\ldots]^{\prime 45}$. La referència reiterada en tots els parts a la "cadira de les parteres", també ens mostra la penetració de pràctiques procedents de la medicina clàssica grega, com també la idea que s'han de complir els desitjos de les embarassades ${ }^{46}$.

Les referències sobre la lactància són diverses, però només en una ocasió es matisa la seua duració: "La mare el va alletar durant dos anys i després el deslleta"47. També és evident que segons la classe social de la dona és ella o les nodrisses qui criarà el lactant ${ }^{48}$.

La pràctica de la poligàmia, es manifesta en la distinció entre "germanes uterines" 49 i germanes de pare, ${ }^{50}$ segons les mares foren

44 Nit 67, vol. I, pàg. 398. En altres contes es manifesten idees semblants: nit 22, vol. I, pàg. 152; nit 109, vol. I, pàg. 511.

${ }^{45} \mathrm{Nit} 109$, vol. I, pàgs. 511-512. La mateixa descripció del part en les històries de la nit 45, vol. I, pàg. 314: "Així se'n va eixir dels comptes i va seure a la cadira de parts". També en la nit 6, vol. I, pàg. 399: "La jove va seure a la cadira de les parteres, Déu li va facilitar el part i va donar a llum una xiqueta".

${ }^{46} \mathrm{Nit} 714$, vol. II, pàg. 650 . Alí, disfressat de dona embarassada li diu a Zurayq, que està fregint peix: "sóc una dóna embarassada... Dóna'm un tros de peix per a ella, que el fetus es mou en el seu ventre".

${ }^{47}$ Nit 484, vol. II, pàg. 4.

${ }^{48}$ Nit 23, vol. I, pàg. 153: "Van tallar el cordó umbilical, li van posar col-liri als ulls, i li'l van lliurar a la nodrissa". En una altra història, nit 109, vol. I, pàg. 512: "Les nodrisses van agafar el nou nascut, van tallar el cordó umbilical i li van posar col-liri als ulls [...] Va ser alletat entre carícies i criat en el si del benestar".

${ }^{49}$ Nit 28, vol. I, pàg. 204.

${ }^{50} \mathrm{Nit} 59$, vol. I, pàg. 382. 
les mateixes o no. Però en tot cas, el vincle sanguini marcarà per a sempre com una tendència irresistible: "la veu de la sang"51.

Pel que fa al contingut en dades sobre patologia clínica i terapèutica es molt dispers $\mathbf{i}$ se solen mesclar elements cientffics $\mathbf{i}$ creences. Les malaties que s'esmenten són la verola ${ }^{52}$, la lepra ${ }^{53}$, l'epilepsia ${ }^{54}$, la bogeria ${ }^{55}$, i poc més. Respecte a les causes de malaltia, en ocasions se n'al-ludeix alguna de la sex res non naturales ${ }^{56}$, però possiblement la

51 "La veu de la sang portava al tuguri" on vivia son pare, que ell no coneixia, nit 23, vol. I, pàg. 162. En un altre lloc, Sankan, en veure la seua germana de pare, la princesa Nuzhat al-Zaman, sense saber qui era "es va sentir atret per la veu de la sang", i van consumar immediatament l'incest; nit 67, vol. I, pàg. 398.

$52 \mathrm{Nit} \mathrm{25,} \mathrm{vol.} \mathrm{I,} \mathrm{pàg.} 173$.

${ }^{53}$ Nit 4, vol. I, pàg 33.

$\$ 4$ Nit 951 , vol. II, pàg. 1.327.

55 Nit 704, vol. II, pàg 622.

56 Segons l'esquema galènic, les causes externes de la malaltia serien sis coses no-naturals. És a dir, allò que no pertany a la naturalesa de l'home però en ocasions, i segons la constitució de cadascun, pot ser origen de la malaltia. Aquestes sis coses són: menjar-beure, treball-descans, son-vigília, aire-ambient, excrecions-secrecions i els moviments de l'ànim. En les diverses històries de l'obra, el menjar pot corrompre la naturalesa, nit 116, vol. I, pàg 532; i l'aire pot ser causa de malaltia, nit 33, vol. I, pàg. 250 i nit 704, vol. I, pàg. 622.

En moltes ocasions s'al-ludeix als "menjadors de haixix" $i$ les seues conseqüències: nit 21, vol. I, pàg. 364. Però el passatge en el qual es descriu amb gran riquesa de detalls les al lucinacions produïdes pel haixix és en la nit 143 , vol. I, pàgs. 630-31:

"Després va anar a buscar el safareig d'aigua freda i com que no va trobar ningú, s'hi va instal' lar, va agafar un tros de haixix i se'l va engolir. Li va pujar de seguida al cervell i va caure desmaiat damunt el marbre. El haixix el va fer creure que un gran personatge li feia un massatge i que dos esclaus es mantenien de peus al costat del seu cap.

Un d'ells tenia en la mà una tassa i l'altre els instruments del banyador $\mathrm{i}$ tot el necessari per al bany. En veure'ls va dir: "Sembla que aquests s'equivoquen amb mi o bé tenen el mateix vici, són menjadors de haixix". Va estendre el peus i va creure que el banyador li deia: "Senyor meu! S'aproxima el moment de la teua eixida: avui toca servir-te" Es va posar a riure i va dir: "Ets meravellós, haixix!" Va seure i va callar.

El banyador se li va apropar, el va prendre de la mà, li va posar un cinturó de seda negra i se'n van anar seguits per dos esclaus amb les tasses i la resta d'estris. No es van detenir fins a entrar en una habitació solitària, 
més important, pel tipus del gènere, són els "moviments d’ànim": la por ocasiona diarrea ${ }^{57}$, els gels "emmalalteixen el cos ... i canvien el color" ${ }^{58} \mathrm{i}$, sobretot, el sentiment amorós és la causa d'una patologia variada $i$, fins $\mathrm{i}$ tot, de mort ${ }^{59}$. Sens dubte, la història més poètica és la narrada en la nit 384, en la qual l'enamorat malalt sol-licita a la seua

que van perfumar. Estava plena de tota classe de flors i perfums. Van obrir un meló, van fer que seguera en una butaca d'eben i el banyador va continuar llavant-lo mentre els dos esclaus el ruixaven d'aigua. Després li van donar bones fregues $i$ li van dir: "Senyor nostre! Déu vulga que sigues sempre feliç!". Se'n van anar i van tancar la porta. Quan va imaginar tot açò, es va posar dempeus, es va llevar el cinturó i va començar a riure fins a caure desmaiat. Va continuar rient una estona i després es va dir a si mateix: "Què deu passar perquè em parlen com si fóra un visir i em donen el tractament de senyor nostre? Potser s'han confós un moment, però aviat em reconeixeran i diran que sóc un neci i em molestaran a bescollades".

A continuació va prendre el bany i va obrir la porta; va creure que un jove mameluc $i$ un eunuc se li presentaven. El mameluc portava un paquet. El va obrir i va treure tres tovalloles de seda. Li'n va posar una al cap, una altra als muscles i li va cenyir la tercera a la cintura. L'eunuc li va calçar unes sandàlies; de seguida es van acostar mamelues i eunucs i el van ajudar. A tot açò ell no feia altra cosa que riure. Va eixir i es va dirigir a la sala; va trobar un gran llit que era digne d'un rei. Els criats van córrer a servir-lo, el van fer seure al llit i van començar a donar-li un massatge fins que es va quedar dormint. En somnis va veure una joveneta descansant. La va besar, la va col locar entre les seues cames i es va situar de la manera que l'home adopta amb la dona. Va agafar el membre amb la mà, va atraure vers ell la noia i la va estrényer davall.

En aquest moment una veu va dir: "Desperta, ase! És migdia i encara dorms!". Va obrir els ulls $i$ es va veure al costat del recipient d'aigua freda; al voltant hi havia una multitud que reia mentre el seu membre es mantenia trempat i la tovallola de la cintura s'havia obert per la meitat. Es va adonar que tot havia estat un somni confús o visions produïdes per l'opi. Es va quedar trist, va mirar vers el que l'havia despertat i va dir: "Esperava ficar-lo!". La gent li va dir: "No et fa vergonya, menjador de haixix, dormir amb el teu membre trempat?". Li van donar bescollades fins que el bescoll se li va posar vermell. Estava afamat, però havia tasta el menjar de la felicitat al somni".

${ }^{57} \mathrm{Nit} 21$, vol. I, pàg 146.

${ }^{58} \mathrm{Nit} 53$, vol. I, pàg. 360.

${ }^{59}$ Nit 384, vol. I, pàg 1251 ; nit 688-691, vol. II, pàgs. 574-581; nits 948953, vol. II, pàgs 1311-1331. 
estimada que el visite, i ella es nega fins que l'anuncien que esta a punt de morir:

"Aleshores es va entendrir i li va fer l'honor d'anar a visitar-lo. Els ulls del malalt, en veure-la, s'ompliren de llàgrimes, i va recitar:

Per la teua vida! Si passa el meu enterrament pel teu costat i els baiards van a muscles de quatre homes, no seguiràs el seguici per a saludar la tomba d'un mort depositat en el fossar?

Ella, en sentir aquestes paraules, va plorar molt i va dir: Per Déu! Mai no haguera cregut que el teu amor per mi haguera arribat fins a aquest punt, fins a posar-se en braços de la mort! Si ho haguera sabut t'hauria auxiliat i m'haguera donat a tu. L'home, en sentir les seues paraules, va vessar llàgrimes tan abundants com la pluja i va recitar aquestes paraules del poeta:

$S$ 'ha acostat quan la mort s'interposava entre ella $i$ jo $i$ ha oferit la unió quan la unió ja no servia de res.

Va patir una ranera i va morir. Ella es va llançar damunt d'ell per besar-lo i plorar. Va plorar sense parar fins que va caure desmaiada al seu costat. En tornar en si va recomanar als seus familiars que la soterraren en la mateixa tomba quan morira. Amb els ulls plens de llàgrimes va recitar aquest parell de versos:

Hem viscut sobre la terra una vida agradable: la tribu, la família i la pàtria estaven contents amb nosaltres.

El destí i la sort van trencar la nostra companyia i el sudari ens ha reunit en el seu interior.

En acabar els versos va plorar de nou $i$ va continuar plorant $i$ sanglotant fins que va caure desmaiada. Va romandre així tres dies $\mathrm{i}$ després va morir. La van soterrar en la mateixa tomba que el jove. Aquesta és una de les històries d'amor més meravelloses".

La presencia de la patologia galenico-tradicional, es manifesta també en pràctiques com prendre el pols ${ }^{60}$ i la utilització de la teoria humoral per a explicar algunes alteracions, com la ira de l'individu de

${ }^{60}$ Nit 27, vol. I, pàg. 198. 
temperament coleric ${ }^{61}$ que, en ocasions, provoca que li "esclafira la bufeta del fel"62.

Juntament amb aquest tipus de malalties més fonamentades en la medicina, estan les de la medicina popular. La més important és el "mal d'ull", quasi sempre causat per l'enveja: "En adonar-se'n com de bells i ben proporcionats els havia fet Déu (als fills d'Abd al-Rahman), va tenir por del mal d'ull que pogueren causar-los les que els veieren $[\ldots]^{1163}$.

Per últim, respecte a la terapèutica, s'usen matèries i procediments procedents de la medicina clàssica com la sagnia i els farmacs simples, junt amb unes altres d'origen popular clar ${ }^{64}$.

En definitiva, i com a conclusio, podem afirmar que les idees i les pràctiques mediques en les Mil $i$ una nits, són un reflex fidel de la realitat històrica dels períodes en que van ser redactades. El seu fonament és l'assimilació de la medicina clàssica grega i hel-lenística $\mathrm{i}$ juntament amb aquesta trobem elements procedents d'altres cultures $\mathrm{i}$ de la mateixa tradició popular, sense que aixo altere la coherència d'aquesta.

${ }^{61}$ Nit 29, vol. I, pàg 208.

${ }^{62}$ Nit 120 , vol. I, pàg. 541.

${ }^{63} \mathrm{Nit} 963$, vol. II, pàgs. 1369-70. A més, aquesta malatia apareix en: nit 21, vol. I, pàg. 147 i nit 132, vol. I, pàg. 565.

${ }^{64}$ Se sana un leprós amb drogues simples per absorció de la mà, (nit 4, vol. I, pàgs. 33-34); s'usa sal i pòlvores per a tallar l'hemorràgia (nit 27, vol. I, pàg. 197 i nit 32, vol. I, pàg. 233). La pràctica de la sagnia va unida en ocasions a creences alienes a la medicina clàssica, com l'ús de l'astrolabi per a indicar la pertinença $o$ no de les pràctiques esmentades, segons la tradició astrològica persa (nit 29, vol. I, pàg. 209); o se sagna el divendres per no perdre "mai la vista $\mathrm{i}$ evitar moltes malalties" segons una dita d'origen alcorànic (nit 28 , vol. I, pàg. 209). 